\title{
The nature and position of processing determines why forgetting occurs in working memory tasks
}

\author{
Christopher JaRrold ANd Helen TAM \\ University of Bristol, Bristol, England \\ Alan D. Baddeley \\ University of York, York, England \\ AND \\ Caroline E. Harvey \\ University of Bristol, Bristol, England
}

\begin{abstract}
The effect of potentially distracting processing within working memory was examined by varying the nature and position of processing across conditions of a Brown-Peterson-like task. Separate groups of participants carried out verbal or visuospatial processing operations on identical stimuli, while retaining lists of to-beremembered words. The number of words presented either before or after the processing interval was varied systematically. Results showed that although verbal processing was no more demanding than visuospatial processing, it led to greater forgetting. However, forgetting was confined to items presented prior to processing, and the difference in degree of forgetting shown by the two groups was maximal when four items occurred before processing. Temporal isolation effects were more marked in the verbal processing group. These findings indicate that individuals can keep active a limited number of items in primary memory during processing, unless processing blocks rehearsal, in which case retrieval occurs from secondary memory.
\end{abstract}

Many influential models of memory eschew a distinction between the memory systems that operate over shortand long-term time scales, claiming instead that the same principles govern forgetting and retention over all time intervals (e.g., Brown, Neath, \& Chater, 2007; Nairne, 1990). In addition, a typical characteristic of such models is that forgetting is thought to result from interference, as a result of either the featural (Nairne, 1990) or the temporal (Brown et al., 2007) similarity of the items encoded into memory. Certainly, "temporal distinctiveness" effects on memory performance can be demonstrated, such that items that are presented in relative temporal isolation are easier to recall than items that are presented among competitors with relatively close temporal proximity (Brown et al., 2007; Crowder, 1976).

An alternative view is that different memory systems and processes underpin memory over short- and long-term time scales (e.g., Baddeley \& Hitch, 1974; Waugh \& Norman, 1965), with the distinction between the two typically centering on whether items are "held active" over shortterm intervals. For example, in Baddeley's (1986) model, to-be-remembered information is actively maintained in short-term memory whenever possible - in the case of verbal memoranda, by a process of subvocal rehearsal.

Recently, Unsworth and Engle (2007) applied this distinction to the study of working memory performance.
By definition, working memory tasks require individuals to attempt to maintain information in the face of potentially distracting processing operations, and Unsworth and Engle suggested that this requires a combination of "primary" and "secondary" memory (cf. Waugh \& Norman, 1965). Whereas primary memory involves the active maintenance of items, retrieval from secondary memory involves cue-dependent search of long-term memory representations. The capacity of primary memory is, therefore, likely to be affected by an individual's ability to rehearse, whereas interference effects are expected when retrieval from secondary memory is required. Indeed, Unsworth, Heitz, and Parks (2008) showed that temporal distinctiveness effects operate in a Brown-Peterson paradigm, in which storage items are followed by a period of processing operations that are assumed to block rehearsal.

The present study extended Unsworth et al.'s (2008) procedure in a novel manner to explicitly test the prediction that interference effects operate only when tobe-remembered items cannot be held active in primary memory. To that end, a Brown-Peterson-like design was adopted in which participants had to recall six-item lists of words that were presented in conjunction with a block of potentially distracting processing operations. However, two important modifications to a standard Brown-

C.Jarrold, c.jarrold@bristol.ac.uk 
Peterson design were made. First, the type of processing employed was manipulated between participants. Although all participants were presented with the same stimuli in the processing phase, one group was required to make verbal judgments on these items thought to disrupt rehearsal, while a second group was asked to make visuospatial judgments that were designed to be at least as difficult. Second, the structure of the task was manipulated within participants by systematically varying the position of the block of processing relative to the presentation of the to-be-remembered items; in each condition of the task, between 0 and 6 memoranda were presented before the processing interval, with the remaining 6 to 0 memoranda presented after the processing block (see Figure 1).

These novel manipulations allowed us to ask two important questions about the extent to which forgetting from working memory is driven by the nature of the processing employed in a given task condition. First, according to Baddeley (1986), processing demands inherent in a working memory task will block or disrupt rehearsal only if they recruit articulatory planning systems. In contrast, the time-based resource-sharing model (TBRS; Barrouillet, Bernardin, Portrat, Vergauwe, \& Camos, 2007 ) assumes that processing leads to forgetting because it prevents a domain-general "attentional refreshment" of memory traces by capturing attention itself. Barrouillet and colleagues, therefore, argued that it is the cognitive load associated with a processing operation that is the primary determinant of the disruption caused to memory, and not the nature (verbal or nonverbal) of the processing per se (see also Vergauwe, Barrouillet, \& Camos, 2010). By embedding verbal and nonverbal processing episodes of broadly comparable difficulty within our working memory task, we were able to test the extent to which the nature of any processing is relevant to the degree of forgetting caused once cognitive load is accounted for.

Second, by moving the processing relative to the position of the presentation of storage items, one can determine whether any effects of forgetting that are caused by the imposition of processing are proactive or retroactive, as well as calculate the number of items over which these effects operate. Different models make intriguingly different predictions in this regard. In Nairne's (1990) feature model, features within an item's representation in memory may be overwritten by a succeeding item containing a different value for that feature, leading to oneitem retroactive interference. Farrell and Lewandowsky's (2002) SOB (serial-order-in-a-box) model assumes that the strength with which an item is encoded depends on its similarity to items already encoded in memory; processing operations that share features with subsequent storage items would therefore exert proactive interference on these subsequent memoranda. Brown and colleagues' SIMPLE (scale-independent memory, perception, and learning) model (Brown et al., 2007) assumes that items that share featural similarity will interfere with each other but the degree of any such interference will also be moderated

\section{Condition}

\begin{tabular}{|c|c|c|c|c|c|c|c|c|c|c|c|}
\hline OP6 & \multicolumn{4}{|c|}{ Processing interva } & & & $\mathrm{I}_{2}$ & $\mathrm{I}_{3}$ & $\mathrm{I}_{4}$ & $\mathrm{I}_{5}$ & $\mathrm{I}_{6}$ \\
\hline $1 \mathrm{P} 5$ & $\mathrm{I}_{1}$ & \multicolumn{5}{|c|}{ Processing interval } & $\mathrm{I}_{2}$ & $\mathrm{I}_{3}$ & $\mathrm{I}_{4}$ & $\mathrm{I}_{5}$ & $\mathrm{I}_{6}$ \\
\hline $2 \mathrm{P} 4$ & $\mathrm{I}_{1}$ & $\mathrm{I}_{2}$ & \multicolumn{5}{|c|}{ Processing interval } & $\mathrm{I}_{3}$ & $\mathrm{I}_{4}$ & $\mathrm{I}_{5}$ & $\mathrm{I}_{6}$ \\
\hline $3 \mathrm{P} 3$ & $\mathrm{I}_{1}$ & $\mathrm{I}_{2}$ & $\mathrm{I}_{3}$ & \multicolumn{5}{|c|}{ Processing interval } & $\mathrm{I}_{4}$ & $\mathrm{I}_{5}$ & $\mathrm{I}_{6}$ \\
\hline $4 \mathrm{P} 2$ & $\mathrm{I}_{1}$ & $\mathrm{I}_{2}$ & $\mathrm{I}_{3}$ & $\mathrm{I}_{4}$ & \multicolumn{5}{|c|}{ Processing interval } & $\mathrm{I}_{5}$ & $\mathrm{I}_{6}$ \\
\hline $5 \mathrm{P} 1$ & $\mathrm{I}_{1}$ & $\mathrm{I}_{2}$ & $\mathrm{I}_{3}$ & $\mathrm{I}_{4}$ & $\mathrm{I}_{5}$ & \multicolumn{5}{|c|}{ Processing interval } & $\mathrm{I}_{6}$ \\
\hline $6 \mathrm{PO}$ & $\mathrm{I}_{1}$ & $\mathrm{I}_{2}$ & $\mathrm{I}_{3}$ & $\mathrm{I}_{4}$ & $\mathrm{I}_{5}$ & & & Proc & ssin & inte & \\
\hline
\end{tabular}

Figure 1. Schematic illustration of the design of the seven conditions of the working memory task $(X P Y=X$ items presented prior to processing, and $Y$ items presented after processing. $\mathrm{I}_{x}=x$ th to-be-remembered item; processing interval consists of 18 sec of either verbal or visuospatial decisions on letter pairs; see the text). 
by the temporal distinctiveness of these items. Following Unsworth et al. (2008), we predicted temporal distinctiveness effects, but only for items presented prior to the onset of verbal processing, which we assumed would prevent the active maintenance of these items in primary memory. In contrast, such effects were not expected for items that occurred prior to visuospatial processing, since it was assumed that rehearsal of such items would be possible during the processing phase.

\section{METHOD}

\section{Participants}

Forty-two undergraduates took part in this experiment and received either course credit or $£ 7$ remuneration. Participants were randomly assigned to one of two processing groups, with 21 participants receiving the verbal processing versions of the tasks described below and 21 receiving the visuospatial processing versions.

\section{Procedure}

Each participant began and ended the experimental session with a "baseline processing" task in which they carried out a series of processing judgments in the absence of any memory load. In between these two baseline processing tasks, participants carried out the seven conditions of the working memory task.

Processing judgments. The processing judgments required in the tasks described below all involved the presentation of a pair of uppercase letters that appeared in 96-point Arial font in the center of the screen, spaced by $9 \mathrm{~cm}$. Participants in the verbal processing group were instructed to decide whether the two letters rhymed (e.g., $\mathrm{C}$ and $\mathrm{P}$ ). Participants in the visuospatial processing group were asked to judge whether the two letters shared an axis of symmetry, which could be either vertical (e.g., A and T) or horizontal (e.g., $\mathrm{D}$ and $\mathrm{K}$ ). In both groups, participants responded by pressing the "p" key for a "yes" response and the "q" key for a "no" response. Each letter pair was drawn from a pool of 12 items (A, C, D, E, G, I, J, K, $\mathrm{P}, \mathrm{T}, \mathrm{V}$, and $\mathrm{Y}$ ), and was selected so that $50 \%$ of the pairs were associated with a "yes" response in each condition. For the two baseline tasks, and within each trial during each of the seven conditions of the working memory task, a single version of a letter-pair sequence was presented to both processing groups in the same predetermined, randomized order.

Baseline processing tasks. Each baseline processing task began with 4 practice trials, followed by 30 trials from which data were recorded. The presentation of each letter pair was preceded by a fixation cross for $250 \mathrm{msec}$, followed by a 25 -msec blank screen, followed by the two letters. Once a participant made his or her response to a letter pair, the next fixation cross and subsequent letter pair were presented immediately.

Working memory task. Each of the seven working memory conditions involved the presentation of six to-be-remembered words and a processing interval of 18 -sec duration. The to-be-remembered words were presented visually in 72-point Arial font for a duration of $750 \mathrm{msec}$, followed by a blank screen for $250 \mathrm{msec}$. Words were drawn from a pool of 60 two-syllable words (e.g., extent, vision, closer, answer, purpose, respect) that were of relatively low concreteness and imageability values according to the MRC Psycholinguistic Database (Coltheart, 1981) $(M=331, S D=47$, for concreteness; $M=372, S D=53$, for imageability). Each condition consisted of 10 trials, so that each word was presented once in every condition, although the ordering of words within lists was varied systematically across conditions.

The processing block was identical in form to the baseline processing task described above, with the exception that the participant made as many responses as were required to make this section of the trial last $18 \mathrm{sec}$. The seven task conditions were formed by the systematic "shifting" of this processing episode relative to the six storage items (see Figure 1).
Table 1

Reaction Times (for Correct Responses Only) and Accuracy for Baseline Processing Tasks and for Processing Within the Working Memory Task (Averaged Across Conditions)

\begin{tabular}{|c|c|c|c|c|c|}
\hline \multirow[b]{2}{*}{ Task } & \multirow{2}{*}{$\begin{array}{l}\text { Processing } \\
\text { Group }\end{array}$} & \multicolumn{2}{|c|}{$\begin{array}{c}\text { Reaction } \\
\text { Times }(\mathrm{msec})\end{array}$} & \multicolumn{2}{|c|}{$\begin{array}{l}\text { Accuracy } \\
\text { (\% correct) }\end{array}$} \\
\hline & & $M$ & $S D$ & $M$ & $S D$ \\
\hline \multirow[t]{2}{*}{ Initial baseline } & Verbal & 1,416 & 493 & 95.87 & 5.76 \\
\hline & Visuospatial & 1,855 & 585 & 96.67 & 4.22 \\
\hline \multirow[t]{2}{*}{ Working memory } & Verbal & 1,164 & 347 & 94.70 & 3.33 \\
\hline & Visuospatial & 1,122 & 225 & 95.31 & 3.48 \\
\hline \multirow[t]{2}{*}{ Final baseline } & Verbal & 957 & 267 & 96.35 & 3.64 \\
\hline & Visuospatial & 932 & 199 & 97.62 & 3.96 \\
\hline
\end{tabular}

In all conditions, participants were instructed to recall items verbally in correct serial order in response to the appearance of a question mark at the end of each trial. They were allowed to omit responses if they wished. Recall performance was scored in terms of the percentage of items recalled at each serial position within the presented list. The order of presentation of conditions was counterbalanced using a Latin square design.

\section{RESULTS}

\section{Baseline Processing Performance}

Reaction times (for correct responses only) and levels of accuracy for the two groups' performance on the baseline processing tasks are given in Table 1. An ANOVA of these data showed a trend toward a significant effect of group on correct reaction times $\left[F(1,40)=3.33, M S_{\mathrm{e}}=\right.$ $\left.269,596, p=.08, \eta_{\mathrm{p}}^{2}=.08\right]$ that was qualified by a significant group $\times$ time-point interaction $[F(1,40)=14.35$, $\left.M S_{\mathrm{e}}=78,403, p<.01, \eta_{\mathrm{p}}^{2}=.26\right]$. The latter reflected significantly longer reaction times among the visuospatial processing group than among the verbal processing group at the initial assessment $\left[F(1,40)=6.90, M S_{\mathrm{e}}=292,584\right.$, $\left.p=.01, \eta_{\mathrm{p}}^{2}=.15\right]$, coupled with no significant difference between groups at the final assessment $(F<1)$. The corresponding analysis of accuracy revealed a nonsignificant main effect of group and a nonsignificant interaction with time-point (both $F \mathrm{~s}<1$ ).

\section{Working Memory Performance}

A preliminary analysis of the average reaction time and accuracy for processing responses made by each group during the working memory task (averaged across conditions; see Table 1), showed no evidence of a significant difference in processing difficulty (both $F_{\mathrm{s}}<1$ ).

Recall performance on the seven working memory conditions is plotted by group in Figure $2 .{ }^{1}$ An omnibus ANOVA with the factors of group, condition, and serial position revealed a significant three-way interaction $\left[F(30,1200)=2.07, M S_{\mathrm{e}}=270.02, p<.01, \eta_{\mathrm{p}}^{2}=.05\right]$, reflecting differential group $\times$ serial position interactions across conditions. These group $\times$ serial position interactions are shown in Table 2, which also presents main effects of group for each condition.

Table 2 shows that the main effect of group was significant for the 4P2 condition only, due to poorer overall recall among individuals in the verbal processing group than among those in the visuospatial processing group. The 


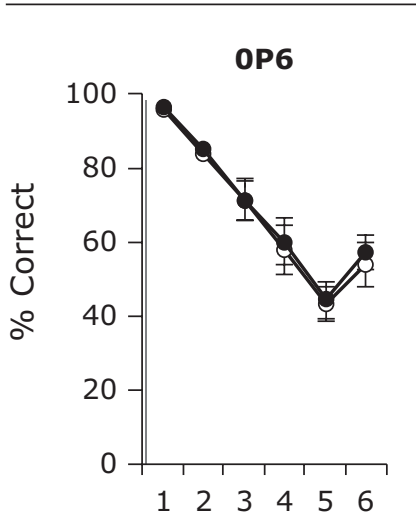

Serial Position

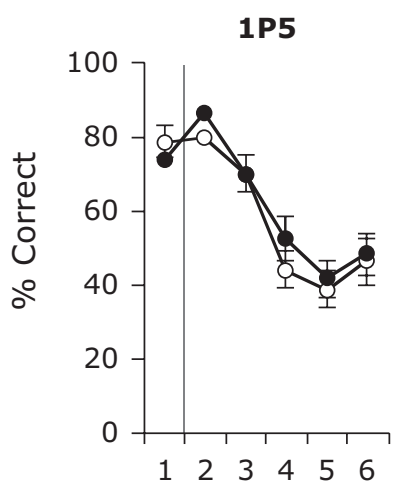

Serial Position

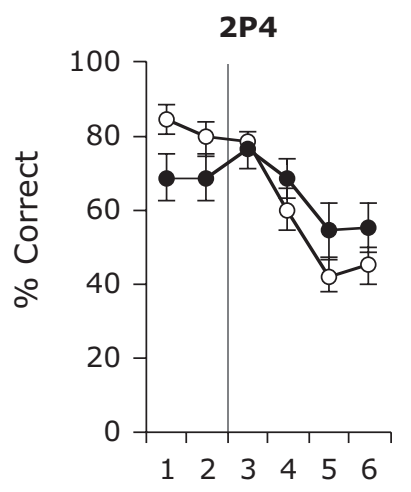

Serial Position

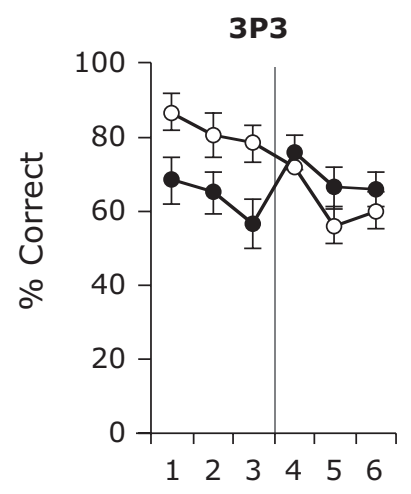

Serial Position
4P2

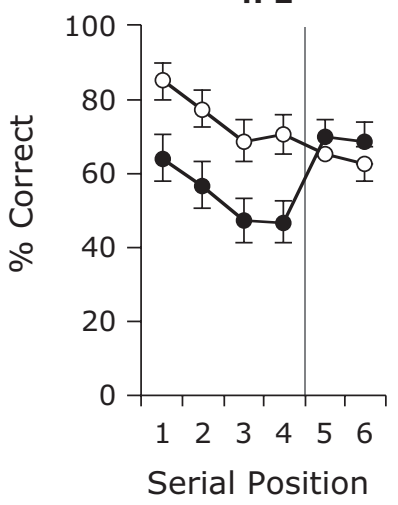

$5 P 1$

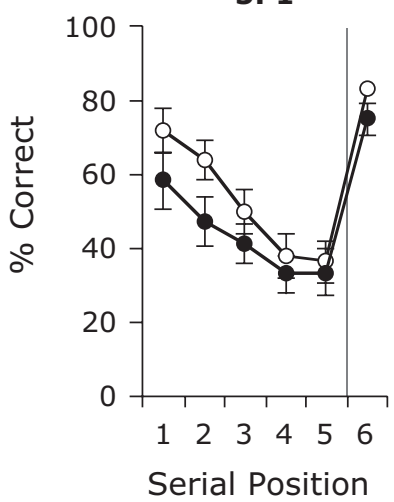

6P0

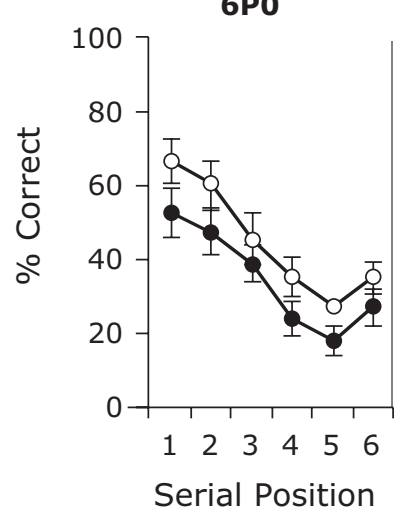

Processing Group

$\rightarrow$ Verbal

$\infty$ Visuospatial

Figure 2. Mean recall performance by both groups on each of the seven working memory conditions. Position of processing is shown by the dashed line in each panel. Error bars are \pm 1 standard error of the mean.

group $\times$ position interaction was significant for the $2 \mathrm{P} 4$, $3 \mathrm{P} 3$, and 4P2 conditions, and these interactions were explored further by dividing each condition in two around the position of processing. For the first two items in the $2 \mathrm{P} 4$ condition there was a trend for poorer performance in the verbal processing group than in the visuospatial processing group $\left[F(1,40)=3.29, M S_{\mathrm{e}}=588.15, p=.08, \eta_{\mathrm{p}}^{2}=.08\right]$; the two groups did not differ significantly in their performance on the final four items of the condition $[F(1,40)=$ $\left.1.19, M S_{\mathrm{e}}=482.13, p=.28, \eta_{\mathrm{p}}^{2}=.03\right]$. The verbal processing group showed significantly poorer recall than their counterparts for the first three items of the 3P3 condition $\left[F(1,40)=5.68, M S_{\mathrm{e}}=648.78, p=.02, \eta_{\mathrm{p}}^{2}=.12\right]$, but the

Table 2

Summary of Main Effect of Group and Group $\times$ Position Interaction From Analysis of Each Working Memory Condition

\begin{tabular}{cccccccrr}
\hline & \multicolumn{3}{c}{} & \multicolumn{3}{c}{ Main Effect of Group } & & \multicolumn{3}{c}{$\begin{array}{c}\text { Group } \times \text { Position } \\
\text { Interaction }\end{array}$} \\
\cline { 2 - 4 } \cline { 6 - 8 } Condition & $F(1,40)$ & $p$ & $\eta_{\mathrm{p}}^{2}$ & & $F(5,200)$ & $p$ & $\eta_{\mathrm{p}}^{2}$ \\
\hline 0P6 & 0.10 & .75 & $<.01$ & & 0.05 & .99 & $<.01$ \\
1P5 & 0.30 & .59 & $<.01$ & & 0.82 & .54 & .02 \\
2P4 & 0.01 & .93 & $<.01$ & & 3.35 & $<.01$ & .08 \\
3P3 & 2.31 & .14 & .06 & & 4.33 & $<.01$ & .10 \\
4P2 & 6.37 & .02 & .14 & & 5.06 & $<.01$ & .11 \\
5P1 & 2.39 & .13 & .06 & & 0.73 & .60 & .02 \\
6P0 & 2.97 & .09 & .07 & & 0.32 & .90 & $<.01$ \\
\hline
\end{tabular}

two groups did not differ significantly on the final 3 items of this condition $\left[F(1,40)=1.49, M S_{\mathrm{e}}=327.33, p=.23\right.$, $\left.\eta_{\mathrm{p}}^{2}=.04\right]$. Similarly, this group difference was observed on the first 4 items of the 4P2 condition $[F(1,40)=9.42$, $\left.M S_{\mathrm{e}}=523.32, p<.01, \eta_{\mathrm{p}}^{2}=.19\right]$ but not on the final two items of this condition $(F<1)$.

A final analysis examined the extent to which temporal distinctiveness effects operated to constrain performance by comparing the recall for the item in Serial Position 1 across a series of conditions. Excluding the 0P6 condition, the first item in each list was always presented at the same temporal distance from the point of recall, but the degree of temporal isolation of this item varied across conditions, being maximally distinct in the 1P5 condition (see Figure 1). Figure 3 plots performance by group for the first serial position in these conditions. An ANOVA was conducted on these data with the factors of group and condition, the latter being examined in terms of its linear and quadratic trends. A significant group $\times$ condition interaction was observed for the quadratic trend of condition $\left[F(1,40)=4.98, M S_{\mathrm{e}}=225.53, p=.03, \eta_{\mathrm{p}}^{2}=\right.$ .11]. Among individuals in the verbal processing group, the effect of condition was significantly linear $[F(1,20)=$ $\left.13.16, M S_{\mathrm{e}}=465.31, p<.01, \eta_{\mathrm{p}}^{2}=.40\right]$ but not quadratic $\left[F(1,20)=0.61, M S_{\mathrm{e}}=223.49, p=.44, \eta_{\mathrm{p}}^{2}=.03\right]$. Among individuals in the visuospatial processing group, the linear effect of condition was significant $[F(1,20)=$ 


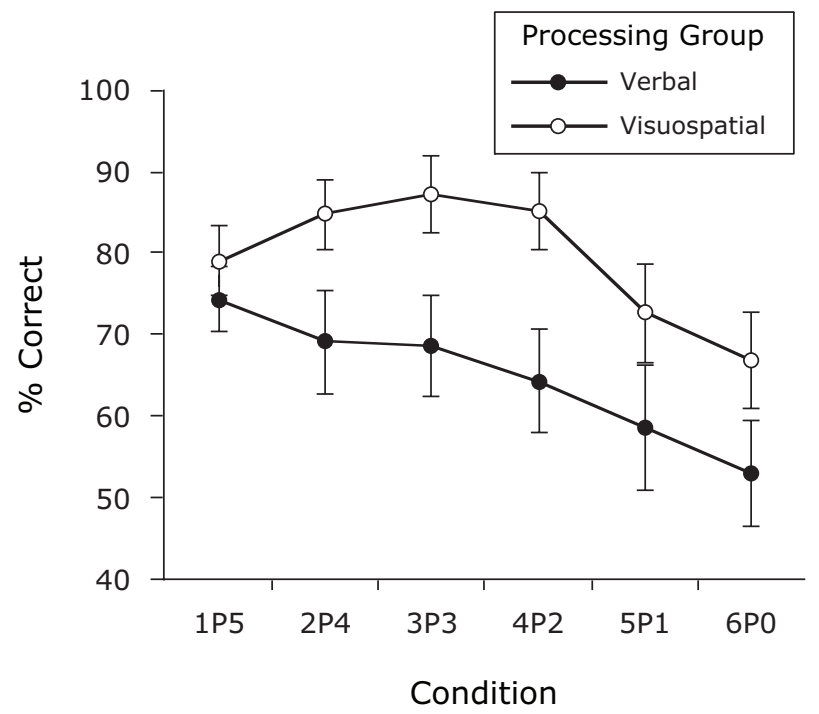

Figure 3. Mean first item recall performance by both groups in conditions in which the first item was presented at a constant temporal distance from the signal to recall. Error bars are \pm 1 standard error of the mean.

6.04, $\left.M S_{\mathrm{e}}=505.84, p=.02, \eta_{\mathrm{p}}^{2}=.23\right]$ but was smaller than the quadratic effect $\left[F(1,20)=15.32, M S_{\mathrm{e}}=227.57\right.$, $\left.p<.01, \eta_{\mathrm{p}}^{2}=.43\right]$. As Figure 3 shows, recall of the first serial position remained high among individuals in the visuospatial processing group for conditions $1 \mathrm{P} 5$ to $4 \mathrm{P} 2$ and dropped only in conditions 5P1 and 6P0.

\section{DISCUSSION}

The aim of this study was to vary the nature and position of processing within a working memory task in order to better understand why the imposition of processing demands in working memory paradigms leads to forgetting, and, in particular, to identify the situations in which processing might prevent items within a working memory paradigm from being held in primary memory.

A first point to note is that the two types of processing given to the separate participant groups were controlled in two important ways. First, the processing manipulation was such that participants performed different operations on exactly the same materials. Second, the data from the baseline processing tasks and the processing performance of individuals within the working memory task showed no evidence that verbal processing was more demanding than visuospatial processing.

Another point to emphasize is that these two groups showed extremely similar levels of recall on the 0P6 condition. In that condition, processing operations were presented prior to all of the storage items, so that the recall demands were similar to those of a simple word span task. That the two groups showed comparable levels of recall in this condition (see Table 2 and Figure 2) confirms that they were well matched for immediate serial recall performance.

These two aspects of the data, therefore, cast the evidence for group differences in the other working memory conditions into clearer light. In essence, Figure 2 shows that verbal processing had a greater effect on items that preceded it than did visuospatial processing, despite the fact that verbal processing was no more difficult than visuospatial processing. Significant differences between the groups were not seen in the 1P5 condition, but presumably this reflects the fact that processing could exert retroactive interference on only one item. In the $2 \mathrm{P} 4,3 \mathrm{P} 3$, and $4 \mathrm{P} 2$ conditions, there were significant interactions between group and position as verbal processing led to impaired recall of items that preceded it, relative to visuospatial processing. As Figure 2 shows, in these conditions, interference was solely retroactive. It also clearly extended across all of the items that had preceded it, rather than being an effect confined to the most recently presented item.

These findings are problematic for a version of the TBRS model that assumes that forgetting in working memory is driven entirely by cognitive load. This would predict at least as much forgetting due to the imposition of visuospatial processing, given that (1) this was at least as difficult as verbal processing and (2) processing operations in all tasks were presented at the same rate. The findings are instead consistent with the most recent instantiation of this account (Camos, Lagner, \& Barrouillet, 2009), which suggests that the nature of processing can have an impact on working memory performance above and beyond any domain-general effects of cognitive load.

The results also pose clear problems for accounts that suggest that forgetting in working memory is solely due to interference between processing operations and memoranda (cf. Lewandowsky, Oberauer, \& Brown, 2009; Oberauer \& Lewandowsky, 2008). The present data count against the feature model because interference is not limited to the item immediately preceding verbal processing, which would be the subject of any overwriting, according to this theory. The data also show no evidence of proactive interference from processing, as would be suggested by the SOB model.

Clearly, one could put forward a pure interference account that assumes that processing has an equivalent effect on any items that precede it. However, the problem with such an account is that, in the current data, the overall effect of verbal processing was not systematically related to the number of items that preceded it. As Table 2 shows, the size of the group effect on recall peaked with the $4 \mathrm{P} 2$ condition and was smaller and nonsignificant in the 5P1 and 6P0 conditions. Indeed, a direct comparison of the size of the group effect on the first four items in the $4 \mathrm{P} 2$ condition with the average of performance on the first four items in the 5P1 and 6P0 conditions showed that the effect was significantly stronger in the former condition $\left[F(1,40)=4.49, M S_{\mathrm{e}}=132.77, p=.04, \eta_{\mathrm{p}}^{2}=.10\right]$. This reduction in degree of forgetting cannot easily be explained by an interference account, which would predict a steady increase in the interference effect as the number of items that precede processing increases.

In contrast, this reduction in effect size can readily be explained by a model that assumes that a limited number of storage items can be kept active in primary memory, and 
that verbal processing of the form employed here blocks rehearsal, thereby reducing this functional capacity. Two aspects of the present data suggest that individuals in the visuospatial processing group were able to rehearse, and keep active in primary memory, an average of four items. First, a comparison of the serial position curves for this group in the 4P2 and 5P1 conditions shows that individuals' recall of items presented before processing dropped substantially across these two conditions. Second, Figure 3 similarly demonstrates that the recall of the first presented item was not detrimentally affected by the imposition of visuospatial processing until five items had to be maintained during the processing interval. The fact that members of the visuospatial processing group could maintain four but not five items in primary memory explains why the processing manipulation had less effect in the 5P1 and $6 \mathrm{P} 0$ conditions than in the 4P2 condition; in the former two conditions, individuals in the visuospatial processing group had to maintain a list of items during processing that was beyond their primary memory capacity, thereby reducing the difference seen between them and the verbal processing group. In line with this suggestion, the analysis of first item recall (see Figure 3) showed clear temporal distinctiveness effects among members of the verbal processing group on recall of the first presented item; recall was superior the more temporally distinct this item was. In other words, when maintenance in primary memory is prevented, interference effects are certainly observed, presumably because recall is taking place from secondary memory.

In sum, the present findings provide further support for the view that working memory tasks often index a mix of primary and secondary memory function, with primary memory capacity being supported by rehearsal that is blocked by verbal processing operations, and with recall from secondary memory being dependent on temporal distinctiveness. However, they extend previous work by showing more clearly the situations in which rehearsal is possible and, by implication, when temporal distinctiveness is not a major determinant of recall. In addition, they provide a means of estimating the functional capacity of primary memory. In this study, individuals were able to maintain four storage items during processing, provided that processing did not preclude rehearsal. It might be noted that this value matches Cowan's (2001) estimate of a three- to four-item focus of attention, and others have drawn a direct link between the capacity of primary memory and the focus of attention (e.g., Unsworth \& Engle, 2007). However, we view this similarity as coincidental and would not necessarily equate these two concepts. Cowan's estimate is the capacity of attention for items in the absence of rehearsal, whereas we argue that an estimate of primary memory should take into account the additional beneficial effect of rehearsal. The present estimate of primary memory capacity is likely to be relatively low because of the length of the to-be-remembered items used here (two-syllable words; cf. Tan \& Ward, 2008). Nevertheless, future work could usefully employ our procedures to determine the relationship between the capacity of primary memory when rehearsal is allowed and the capacity of any focus of attention when rehearsal is prevented.

\section{AUTHOR NOTE}

This work was supported by Grant RES-062-23-1048 from the Economic and Social Research Council of the United Kingdom to the first and third authors. Correspondence concerning this article should be addressed to C. Jarrold, Department of Experimental Psychology, University of Bristol, 12a Priory Road, Bristol BS8 1TU, England (e-mail: c.jarrold@bristol.ac.uk).

Note-Accepted by Cathleen M. Moore's editorial team.

\section{REFERENCES}

BADDEley, A. D. (1986). Working memory. Oxford: Oxford University Press.

Baddeley, A. D., \& Hitch, G. J. (1974). Working memory. In G. H. Bower (Ed.), The psychology of learning and motivation (Vol. 8, pp. 47-89). New York: Academic Press.

Barrouillet, P., Bernardin, S., Portrat, S., Vergauwe, E., \& Camos, V. (2007). Time and cognitive load in working memory. Journal of Experimental Psychology: Learning, Memory, \& Cognition, 33, 570-585. doi:10.1037/0278-7393.33.3.570

Brown, G. D. A., Neath, I., \& Chater, N. (2007). A temporal ratio model of memory. Psychological Review, 114, 539-576. doi:10.1037/ 0033-295X.114.3.539

Camos, V., Lagner, P., \& Barrouillet, P. (2009). Two maintenance mechanisms of verbal information in working memory. Journal of Memory \& Language, 61, 457-469. doi:10.1016/j.jml.2009.06.002

Coltheart, M. (1981). The MRC Psycholinguistic Database. Quarterly Journal of Experimental Psychology, 33A, 497-505. doi:10.1080/14640748108400805

Cowan, N. (2001). The magical number 4 in short-term memory: A reconsideration of mental storage capacity. Behavioral \& Brain Sciences, 24, 87-114. doi:10.1017/S0140525X01003922

Crowder, R. G (1976). Principles of learning and memory. Hillsdale, NJ: Erlbaum.

Farrell, S., \& LeWAndowsky, S. (2002). An endogenous distributed model of ordering in serial recall. Psychonomic Bulletin \& Review, 9, 59-79.

Lewandowsky, S., Oberauer, K., \& Brown, G. D. A. (2009). No temporal decay in verbal short-term memory. Trends in Cognitive Sciences, 13, 120-126. doi:10.1016/j.tics.2008.12.003

NAIRNE, J. (1990). A feature model of immediate memory. Memory \& Cognition, 18, 251-269.

OBerauer, K., \& LeWANDOWSKy, S. (2008). Forgetting in immediate serial recall: Decay, temporal distinctiveness, or interference? Psychological Review, 115, 544-576. doi:10.1037/0033-295X.115.3.544

TAN, L., \& WARD, G. (2008). Rehearsal in immediate serial recall. Psychonomic Bulletin \& Review, 15, 535-542. doi:10.3758/PBR.15 .3 .535

Unsworth, N., \& EnGLe, R. W. (2007). The nature of individual differences in working memory capacity: Active maintenance in primary memory and controlled search from secondary memory. Psychological Review, 114, 104-132. doi:10.1037/0033-295X.114.1.104

Unsworth, N., Heitz, R. P., \& Parks, N. A. (2008). The importance of temporal distinctiveness for forgetting over the short term. Psychological Science, 19, 1078-1081. doi:10.1111/j.1467-9280.2008.02203.x

Vergauwe, E., Barrouillet, P., \& CAmos, V. (2010). Do mental processes share a domain-general resource? Psychological Science, 21, 384-390. doi:10.1177/0956797610361340

Waugh, N. C., \& Norman, D. A. (1965). Primary memory. Psychological Review, 72, 89-104. doi:10.1037/h0021797

\section{NOTE}

1. Across all trials and participants, $61 \%$ of errors were omission errors, $23 \%$ were transposition errors, and $16 \%$ were intrusions.

(Manuscript received January 5, 2010; revision accepted for publication February 28, 2010.) 